\title{
Financing Maternity and Early Childhood Healthcare in The Australian Healthcare System: Costs to Funders in Private and Public Hospitals Over the First 1000 Days
}

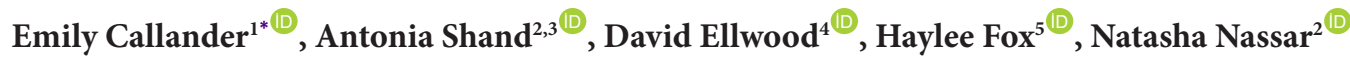

\begin{abstract}
Background: Maternity care is a significant contributor to overall healthcare expenditure, and private care is seen as a mechanism to reduce the cost to public funders. However, public funders may still contribute to part of the cost of private care. The paper aims to quantify (1) the cost to different funders of maternal and early childhood healthcare over the first 1000 days for both women giving birth in private and public hospitals; (2) any variation in cost to different funders by birth type; and (3) the cost of excess caesarean sections in public and private hospitals in Australia.

Methods: This study utilised a whole of population linked administrative dataset, and classified costs by the funding source. The mean cost to different funders for private hospital births, and public hospital births in the Australian state, Queensland are presented by time period and by birth type. The World Health Organization's (WHO's) C-model was used to identify the optimal caesarean section rate based upon demographic and clinical factors, and counterfactual analysis was utilised to identify the cost to different funders if caesarean section had been utilised at this rate across Australia.

Results: We found that for women who gave birth in a public hospital as a public patient, the mean cost was $\$ 22474$. For women who gave birth in a private hospital the mean cost was \$24731, and the largest contributor was private health insurers ( $\$ 11550)$, followed by Medicare (\$7261) and individuals (\$3312). Private hospital births cost government funders $\$ 10050$ on average; whereas public hospital public patient births cost government funders $\$ 21723$ on average and public hospital private patient births cost government funders $\$ 20899$ on average. If caesarean section deliveries were reduced, public hospital funders could save $\$ 974$ million and private health insurers could save \$216 million. Conclusion: Private hospital births cost government funders less than public hospital births, but government funders still pay for around $40 \%$ of the cost of private hospital births. Caesarean sections, which are more frequently performed in private hospitals, are costly to all funders and reducing them could impart significant cost savings to all funders. Keywords: Perinatal Health, Maternal Health, Early Childhood Health, Universal Healthcare, Caesarean Section, Healthcare Costs

Copyright: @ 2021 The Author(s); Published by Kerman University of Medical Sciences. This is an open-access article distributed under the terms of the Creative Commons Attribution License (https://creativecommons.org/licenses/ by/4.0), which permits unrestricted use, distribution, and reproduction in any medium, provided the original work is properly cited.

Citation: Callander E, Shand A, Ellwood D, Fox H, Nassar N. Financing maternity and early childhood healthcare in the Australian healthcare system: costs to funders in private and public hospitals over the first 1000 days. Int J Health Policy Manag. 2021;10(9):554-563. doi:10.34172/ijhpm.2020.68
\end{abstract}

\section{Article History:}

Received: 11 November 2019 Accepted: 1 May 2020 ePublished: 12 May 2020

\section{Key Messages}

Implications for policy makers

- As a result of high caesarean section rates, births in private hospitals are more costly on average than births in public hospitals.

- Although private health insurers pay the most for private hospital births at the time of birth, government funders pay more in the antenatal and postpartum time periods.

- All funders of maternity care would make substantial savings if caesarean section rates were reduced.

Implications for the public

Private hospital births cost public funders less than public hospital births. However, high rates of caesarean section in private hospitals mean that the public, through public hospital funders, could pay less for private hospital births if caesarean section rates were reduced. 


\section{Background}

Maternity care is a unique area of the health system experiencing high volumes of 'patients' and yet not being amenable to prevention or curative initiatives that would see the number of 'patients' decline. Due to this large volume, a considerable amount of healthcare resources are consumed by maternity services and this is expected to continue. ${ }^{1-4}$ Multiple countries are actively seeking ways of improving efficiency and productivity in maternity care, either through the provision of interventions and reform at the point of care, or through structural means such as through the way maternity services are funded. ${ }^{5,6}$ The latter is in recognition of the impact that financing mechanisms can have on the costs of care.

As a part of the funding and delivery of healthcare in general, many countries have a two-tier healthcare system. Under such arrangements, women may access care in public hospitals without any out of pocket fees, or at a heavily subsidised rate. Care may alternatively be accessed through private hospitals and paid for or subsidised by private health insurance coverage held by women. Private hospitals and private providers are used to provide women with greater options in the type of care they receive during pregnancy. ${ }^{7}$ Governments may still contribute to part of the costs of private care, but from a public funder perspective, it is generally considered that having private care as a component in a health system reduces the cost to the public funders. ${ }^{8}$ Such arrangements exist in countries such as Australia, New Zealand, Ireland, Italy, Greece, Spain, France, Germany, the Netherlands, and the United Kingdom. ${ }^{9}$

However, with the provision of maternity care, concern has been raised over the intervention rates in private hospitals, ${ }^{10}$ which are considerably higher than in public hospitals in Australia, France, Greece, Italy, and Ireland. ${ }^{11-15}$ Obstetric interventions include caesarean section, instrumental vaginal delivery, induction of labour and episiotomy, with studies showing caesarean section is one of the most common forms of intervention and is used disproportionately among women accessing private care. ${ }^{11-13}$ The higher rates of intervention in private hospitals are of concern due to the potential negative long-term health outcomes for mother and child, and high costs, part of which may be incurred by public funders. ${ }^{16}$ It is possible that funders currently pay more for private and public maternity care than if interventions, particularly caesarean section, were delivered at optimal rates.

To date, there has been little exploration of the actual costs of maternity care to different funders, nor an assessment of the impact that the caesarean section rate may have on these costs. The consideration of costs to different funders is vital when there are a number of funding sources, as is the case in Australia. Identifying total costs or costs to single funders, which has been done in other studies ${ }^{17-23}$ does not identify who actually pays and whether there is any cost-shifting between funders.

Australia has a mix of public private healthcare. Under the universal healthcare scheme patient treatment within public hospitals for public patients is free-of-charge and funded by the Federal and state governments under public hospital funding agreements. Outside of public hospitals care is partly funded by the Federal government through Medicare with individuals often contributing a co-payment. Prescription pharmaceuticals are also funded by the Federal government through the Pharmaceutical Benefits Scheme (PBS), with patients also paying a small co-payment.

Australia has numerous financial levers to encourage the uptake of private health insurance and the use of private hospital care. ${ }^{24,25}$ These mechanisms are designed to reduce the burden on the public hospital system. ${ }^{26}$ In 2014-2015 within Australia, around half of people aged 18-34 had private health insurance ${ }^{27}$ and in $2015,27 \%$ of women gave birth in a private hospital. ${ }^{28}$ In private hospitals, the hospital stay is funded by the private health insurer if the patient holds the appropriate level of coverage. The medical procedures performed in the private hospital will be partly funded through Medicare, with private health insurers and/or individuals paying a copayment. Individuals can also elect to be admitted to a public hospital as a private patient. In this case the stay is funded by State and Federal governments, with private insurers also paying a co-payment for the stay; and medical procedures are funded through Medicare, and private health insurers and/or individuals also paying a co-payment. As a result, maternal and early childhood care is provided through a mixture of private and public services, with patients being treated between the 2 systems and a variety of funding sources covering the cost of care.

This paper aims to examine the long-term costs of maternity and early childhood healthcare, over the first 1000 days (defined as covering pregnancy, birth and years post-birth ${ }^{29}$ ), to different funders of the health system within the state of Queensland, Australia. This paper also aims to identify the role that caesarean section plays in driving costs to different funders. The paper will answer the following research questions:

1. Who funds public and private births and what are the associated costs to different funders of maternal and early childhood healthcare over the first 1000 days?

2. Do the funder and the cost vary by birth type?

3. What are the estimated costs, and to whom, of excess caesarean sections in public and private hospitals?

\section{Methods}

Data Source

For this study we utilised a whole of population linked administrative dataset, Maternity $1000 .^{30}$ This dataset utilises the Perinatal Data Collection to identify all women who gave birth in the Australian state of Queensland between July 1, 2012 and 30 June, $2015(n=186789)$, plus their babies $(n=189909)$. The records of women and babies were then linked to their Admitted Patient Data Collection, Emergency Department Information System, Clinical Costing Unit, and Medicare Benefits Scheme (MBS) and PBS claims records.

\section{Study Outcomes}

The primary outcomes for this study were the total cost, and cost to each of the following sources of funding:

1. Public hospitals - paid by Federal and state governments through public hospital funding agreements 
2. Medicare - paid by the Federal Government

3. PBS - paid by the Federal Government

4. Private health insurers

5. Individuals

Costs for all health services accessed across the first 1000 days from the estimated date of conception for both mother and child were included. All costs were adjusted to 2017/2018 Australian dollars, based upon Consumer Price Inflation. ${ }^{31}$ Australian dollars are presented throughout. In the Australian healthcare system, women and babies receive care from different providers and in different settings. Because of this, women and babies receive a mix of private and public care, with different funding arrangements.

\section{Cost Measurement}

The actual cost to public hospital funders of each inpatient event in a public hospital was identified from the Clinical Costing Unit dataset. Costs for emergency department presentations were assigned from the Urgency Related Group code listed for each presentation and the corresponding cost listed on the National Hospital Cost Data Collection (NHCDC) produced by the Independent Hospital Pricing Authority (IHPA). ${ }^{32}$

Costs to private health insurers for the hospital stay of private admissions in public and private hospitals were assigned based on the Australian Refined Diagnosis Related Group code of each admission and the corresponding cost reported by the Private Hospital Data Bureau in their Annual Reports. ${ }^{33}$ Costs to Medicare, and to private health insurers for the medical procedures provided to private patients in public and private hospitals were captured on the MBS claims records.

Costs to individuals and Medicare for all other services provided outside of hospitals, or as outpatient services, are captured on the MBS claims records. Costs of prescription pharmaceuticals to the PBS and individuals are captured on the PBS claims records.

The cost of antenatal care was based upon the types of care accessed by each mother and the number of antenatal visits attended, as identified in the Perinatal Data Collection. Women were divided into types of antenatal care and costs assigned as follows:

- Public hospital midwife only: the number of antenatal appointments attended was multiplied by the cost of a midwife antenatal appointment (Tier 2 item 40.28) identified by IHPA on the NHCDC.

- General practitioner (GP) and public hospital midwife only: the number of antenatal appointments was partitioned between GPs and public hospital midwives at a 2:1 ratio, with the cost of GP consultations captured on the MBS dataset, and the cost of midwife consultations taken from the NHCDC (Tier 2 item 40.28).

- Public obstetrician care - no obstetric complications: the number of antenatal appointments was partitioned between public obstetricians and public hospital midwives at a 1:4 ratio, with the cost of public obstetrician consultations taken from the NHCDC for obstetrics consultations for women with no complications (Tier 2 item 20.40), and the cost of midwife consultations taken from the NHCDC.

- Public obstetrician care - with obstetric complications: the number of antenatal appointments was partitioned between public obstetricians and public hospital midwives at a 1:2 ratio, with the cost of public obstetrician consultations taken from the NHCDC for obstetrics consultations for women with complications, and the cost of midwife consultations taken from the NHCDC (Tier 2 item 20.53).

- Private midwife only: it was assumed that the private midwives billed all services through Medicare and thus the costs to Medicare and the patient were captured on the MBS dataset.

\section{Public and Private Classification}

All women and babies were classified based upon their intended place of birth, as being either a:

- ' private birth' - the baby was born in a private hospital, with mother and baby admitted as private patients. Women and babies who were transferred to a public hospital from a private hospital were classified as a private birth, as this was their intended place of birth;

- 'public hospital, public birth' - the baby was born in a public hospital, with mother and baby admitted as public patients;

- 'public hospital, private birth' - the baby was born in a public hospital, with mother and baby admitted as private patients.

Planned homebirths were excluded.

\section{Analysis of Costs}

Descriptive statistics are presented to quantify the cost to different funders based on private or public birth type by important time periods in the first 1000 days (antenatal, birth, year 1 for mother, year 1 for baby, year 2 for mother, year 2 for baby) and mode of birth (vaginal birth, instrumental vaginal birth, cesarean section birth).

\section{Estimation of the Cost of Excess Caesarean Use}

Excess caesarean section use was identified using the World Health Organization's (WHO's) C-Model. ${ }^{34}$ The C-Model is a statistical model that calculates a population's expected caesarean section rate given the population's characteristics (or 'case-mix'). Using the published C-Model parameters and each woman's age, parity, multiple pregnancy, previous caesarean section, gestation at the commencement of labour, fetal presentation, and the onset of labour characteristics ascertained from Maternity1000, each woman's probability of having a caesarean section was calculated. To identify the number of women who would have had a caesarean section in the counterfactual scenario, women were randomly assigned to have a caesarean section or vaginal birth using Monte Carlo simulation..$^{35}$

Amongst those who actually had a caesarean section, but were predicted to have a vaginal birth in the counterfactual scenario, the cost of health service use to different funders was estimated. To estimate these costs, the full Maternity1000 
dataset was limited to women who had a vaginal birth, and a series of generalised linear models were constructed to estimate the cost to different funders, based upon age, parity, multiple pregnancy, gestation at birth, socioeconomic status, pre-existing medical conditions and if the mother had a private birth. A negative binomial distribution and log link function were specified. Separate models were created for each hospital classification.

In order to produce national estimates, the Maternity 1000 dataset was weighted to the Australian population by mother's age, Indigenous identification, and area of residence. Australian benchmarks for these variables were taken from the Australian Institute of Health and Welfare's Mothers and Babies reports relating to the years $2012-2015,{ }^{28}$ to align with each of the years covered by Maternity1000. GREGWT, an algorithm developed by the Australian Bureau of Statistics to weight their population-based surveys, was used to produce the weights. ${ }^{36}$ The mean and summed difference in the actual and counterfactual costs were then presented for public and private births, weighted to the Australian population. All analysis was undertaken in SAS 9.4.

\section{Results}

Between July 1, 2012 and June 30, 2014 in Queensland there 44254 births in a private hospital (28\%), 105343 (68\%) births in a public hospital with mother and baby admitted as a public patient, and 6113 (4\%) births in a public hospital with mother and baby admitted as a private patient. The women had different characteristics based upon the location of birth and funding type. Women who gave birth in private hospitals were older, had a slightly lower body mass index, were less likely to have a medical condition and smoke, and were more likely to be in the highest socioeconomic quintile (Table 1) than women who gave birth in public hospitals. Babies born in private hospitals were less likely to have a 5-minute Apgar score less than 7, and be admitted to the special care nursery or neonatal intensive care unit than babies born in public hospitals. Within public hospitals, women who were admitted as a private patient were slightly older, were less likely to have a medical condition and smoke than women who were admitted as a public patient.

The mean cost for women and their babies who gave birth in a private hospital, over the first 1000 days was $\$ 24731$ (Table 2), which was more than the mean cost for those who gave birth in a public hospital as a public patient or a private patient, for whom the mean cost was $\$ 22474$, and $\$ 23494$ respectively. Table 2 shows the distribution of these total costs across the different funding sources. On average, the largest contributor to the funding of private hospital births was private health insurers (\$11550), followed by Medicare (\$7261). For women and their babies who gave birth in public hospitals the largest funding source on average was public hospital funders, contributing \$17933 for public patients and \$16083 for those who were private patients.

The total costs for women and their babies who gave birth in private hospitals, and for women and their babies who gave birth in public hospitals as public and private patients were highest at the time of birth $\$ 10785, \$ 10926$ and \$11 802 respectively; followed by costs in the antenatal time period $\$ 5257, \$ 3352$ and $\$ 3681$ respectively. For all 3 groups (women and their babies who gave birth in private hospitals, and for women and their babies who gave birth in public hospitals as

Table 1. Socio-Demographic and Infant Characteristics of Women by Birth Location and Funding Type, Queensland, Australia 01/07/2012 - 30/06/2014

\begin{tabular}{|c|c|c|c|}
\hline \multirow{3}{*}{ Characteristic } & \multicolumn{3}{|c|}{ Birth Location and Funding Type } \\
\hline & $\begin{array}{c}\text { Private Hospital, } \\
n=44254 \\
\end{array}$ & $\begin{array}{l}\text { Public Hospital, Public Patient, } \\
\text { n= } 105343\end{array}$ & $\begin{array}{l}\text { Public Hospital, Private Patient, } \\
n=6113\end{array}$ \\
\hline & No. (\%) & No. (\%) & No. (\%) \\
\hline First pregnancy & $15196(34.3)$ & $30030(28.5)$ & $1809(29.6)$ \\
\hline Singleton pregnancy & $42344(95.7)$ & $102644(97.4)$ & $5934(97.1)$ \\
\hline Had a medical condition & $8877(20.0)$ & $28088(26.7)$ & $1269(20.8)$ \\
\hline Smoked before 20 weeks & $713(1.6)$ & $19814(18.9)$ & $653(10.8)$ \\
\hline Indigenous mother & $157(0.4)$ & $9091(8.6)$ & $184(3.0)$ \\
\hline SEIFA quintile 1, (lowest) & $473(1.0)$ & $8641(8.3)$ & $983(16.2)$ \\
\hline SEIFA quintile 2 & $759(1.8)$ & $4152(4.0)$ & $312(5.1)$ \\
\hline SEIFA quintile 3 & $6304(14.6)$ & $24485(23.4)$ & $1306(21.5)$ \\
\hline SEIFA quintile 4 & $18456(42.7)$ & $44459(42.4)$ & $2154(35.4)$ \\
\hline Had a pregnancy complication & $29934(67.6)$ & $69474(66.0)$ & $4032(66.0)$ \\
\hline Gestation at birth less than 37 weeks & $2363(5.3)$ & $5924(5.6)$ & $348(5.6)$ \\
\hline Baby's 5-minute Apgar score less than 7 & $643(1.5)$ & $3096(2.9)$ & $155(2.5)$ \\
\hline Baby admitted to special care nursery & $5786(13.1)$ & $19465(18.5)$ & $1124(18.4)$ \\
\hline Baby admitted to neonatal intensive care unit & $757(1.7)$ & $3106(3.0)$ & $144(2.4)$ \\
\hline Caesarean section birth & $21620(48.9)$ & $29008(27.5)$ & $2063(33.8)$ \\
\hline Mother's BMI, mean \pm SD & $24.6 \pm 5.2$ & $25.7 \pm 6.3$ & $25.7 \pm 5.8$ \\
\hline Mother's age, mean \pm SD & $32.6 \pm 4.5$ & $28.7 \pm 5.8$ & $29.9 \pm 5.5$ \\
\hline
\end{tabular}

Abbreviations: SEIFA, socio-economic index for areas; BMI, body mass index. 
Table 2. Mean Costs to Different Funders of Maternity Care by Birth Location and Funding Type Over the First 1000 Days, Queensland, Australia 01/07/2012 $30 / 06 / 2014$

\begin{tabular}{|c|c|c|c|}
\hline \multirow[b]{2}{*}{ Characteristic } & \multicolumn{3}{|c|}{ Birth Location and Funding Type } \\
\hline & $\begin{array}{l}\text { Private Hospital, } \\
\quad n=44254\end{array}$ & $\begin{array}{l}\text { Public Hospital, Public Patient, } \\
\qquad n=105343\end{array}$ & $\begin{array}{l}\text { Public Hospital, Private Patient, } \\
\qquad n=6113\end{array}$ \\
\hline Total costs & $\$ 24731$ & $\$ 22474$ & $\$ 23949$ \\
\hline Medicare & $\$ 7261$ & $\$ 3539$ & $\$ 4575$ \\
\hline PBS & $\$ 233$ & $\$ 251$ & $\$ 240$ \\
\hline Public hospital funders & $\$ 2557$ & $\$ 17933$ & $\$ 16083$ \\
\hline Private health insurance & $\$ 11550$ & $\$ 272$ & $\$ 1964$ \\
\hline Individual out of pocket & $\$ 3132$ & $\$ 479$ & $\$ 1087$ \\
\hline
\end{tabular}

Abbreviation: PBS, Pharmaceutical Benefits Scheme.

public and private patients) post-birth costs for the mother's healthcare declined in the first year - \$1760, \$1666 and \$1657 respectively; and then increased in the second year $\$ 3131$, \$2225 and \$2458 respectively. Whereas costs for the baby's health service use was higher in the first year post-birth (\$2312, \$2749 and \$2542) and then declined in the second year postpartum (\$1480, \$1548 and \$1802) (Table 3).

There was a large variation in the cost to different funders based upon time period across the first 1000 days. For women and their babies who gave birth in private hospitals, Medicare contributed the largest amount (\$2506) in the antenatal time period, followed closely by individuals in out of pocket payments (\$1965). Whereas at the time of birth private health insurers contributed the largest amount (\$8506). In the first year postpartum Medicare contributed the most to the cost of the mother's health service use (\$760), and Medicare and public hospital funders contributed similar amounts (\$837 and $\$ 836$ respectively) for the baby's health service use. In the second year post-birth private health insurers contributed the most to the cost of the mother's health service use (\$1245), and Medicare and public hospital funders again contributed similar amounts ( $\$ 544$ and $\$ 544$ respectively) for the baby's health service use (Table 3 ).

For women and their babies who gave birth in public hospitals and were admitted as public patients, costs to public hospital funders were the highest in each time period. For women and their babies who gave birth in public hospitals and were admitted as private patients, costs to public hospital funders was also the highest in each time period, except during the antenatal time period and for the mother's healthcare costs in the first year post-birth where costs to public hospital funders and Medicare were similar (Table 3).

For women and their babies who gave birth in private hospitals, and in public hospitals as public and private patients the lowest cost mode of birth was vaginal birth without instruments (\$20964, \$18521 and \$18741 respectively); followed by vaginal births with instruments (\$22723, \$21334 and $\$ 22110$ respectively). The highest cost mode of birth was caesarean section for all 3 groups $(\$ 28244, \$ 31939$, and \$33257) (Table 4).

For women and their babies who gave birth in private hospitals, the costs to Medicare were higher for caesarean section births (\$8091) compared to vaginal births with instruments (\$7309) and without instruments (\$6210). The costs for caesarean sections were also higher for private health insurers (\$13526) compared to vaginal births with instruments (\$10 068) and without instruments (\$9538). The costs to public hospital funders were also higher for caesarean sections in private hospitals (\$3068) compared to vaginal births with instruments in private hospitals (\$1821) and without instruments in private hospitals (\$2144) (Table 4).

For women and their babies who gave birth in a public hospital as public patients, the costs to public hospital funders were substantially higher for caesarean sections (\$26789) compared to vaginal births with instruments (\$16482) and without instruments (\$14291). Costs for caesarean sections were also higher for Medicare (\$3907) compared to vaginal births with instruments (\$3738) and without instruments (\$3350) (Table 4).

For women and their babies who gave birth in a public hospital as private patients, the costs to public hospital funders were higher for caesarean sections (\$22744) compared to vaginal births with instruments $(\$ 15,321)$ and without instruments (\$12267). The costs for caesarean section births were also higher for Medicare (\$5563) compared to vaginal births with instruments (\$4202) and without instruments (\$4052) (Table 4). The costs for caesarean sections were also higher for private health insurers (\$3226) compared to vaginal births with instruments (\$1454) and without instruments (\$1299).

The percentage of women who had a caesarean section birth was higher in private hospitals, with $46 \%$ of women who gave birth in private hospitals having a caesarean section birth compared with $27 \%$ of women who gave birth in a public hospital as a public patient, and $33 \%$ of women who gave birth in a public hospital as a private patient (Table 1). Under the counterfactual scenario, where the probability of having a caesarean section matched the WHO's C-model across Australia, 30\% of women in private hospitals would have a caesarean section, $21 \%$ of women who gave birth in public hospitals as a public patient and $24 \%$ of women who gave birth in public hospitals as a private patient would have done so. In total, public hospital funders were estimated to have saved $\$ 897.7$ million for public hospital, public patient births, and $\$ 48.0$ million for public hospital, private patient births, and \$28.1 million for private hospital births. Private 
Table 3. Mean Costs to Different Funders of Maternity Care by Time of Health Service Use, Queensland, Australia 01/07/2012 - 30/06/2014

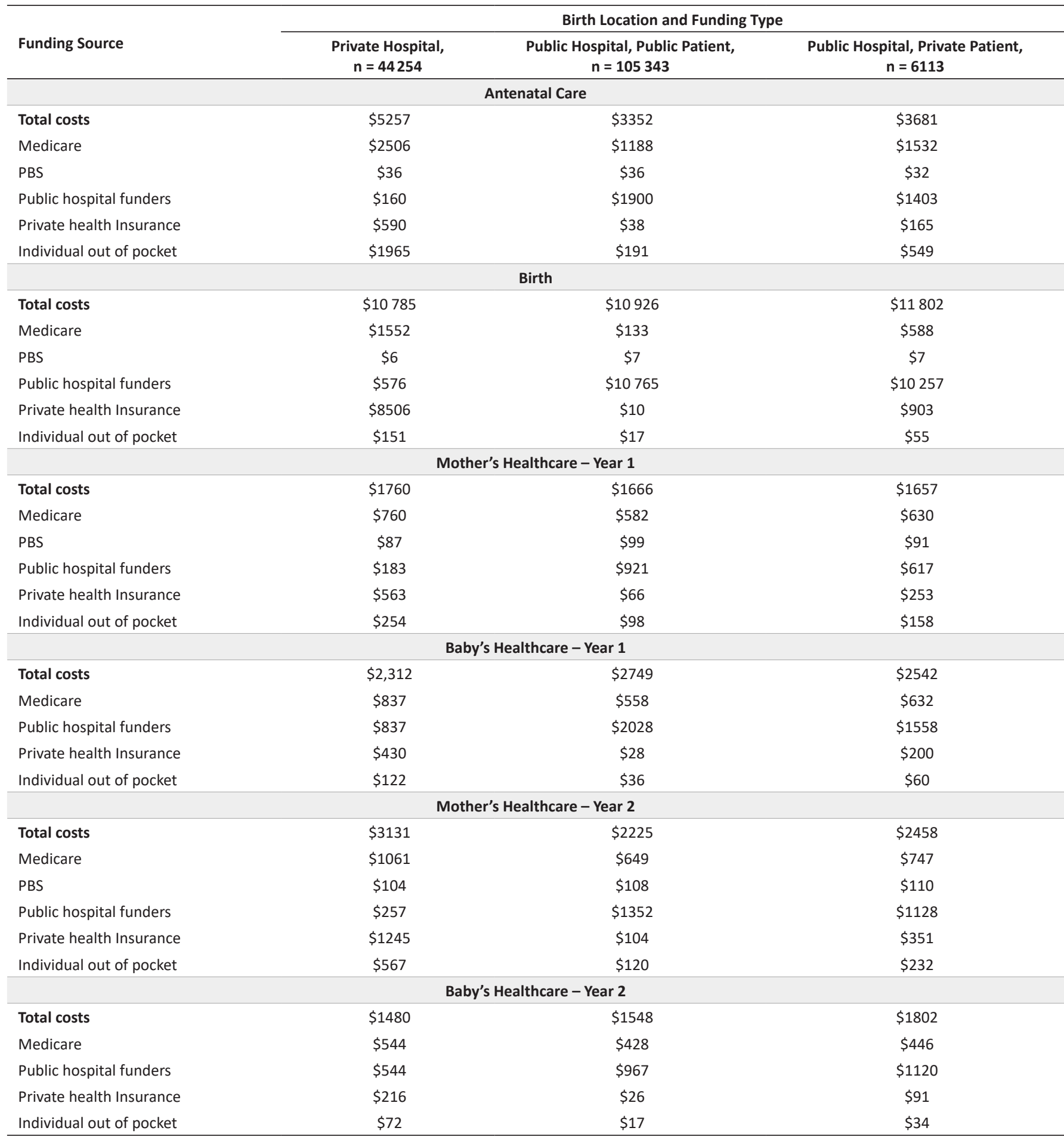

Abbreviation: PBS, Pharmaceutical Benefits Scheme.

health insurers were estimated to have saved $\$ 192.2$ million and Medicare was estimated to have saved $\$ 89.2$ million for private hospital births (Table 5).

\section{Discussion}

The average cost of births over the first 1000 days was lowest for public hospital, public patient births (\$22474). With private hospital (\$24731) and public hospital, private patient (\$23949) births costing more on average, reflective of the higher proportion of birth by caesarean section for these women and their babies. For births in private hospitals, private health insurers contributed an average of $\$ 11550$, which was less than half of the total costs, with Medicare paying \$7261 on average and individuals paying $\$ 3132$ thus making up a large proportion of the total cost. Private health insurers contributed the most at the time of birth (\$8506), but only a small amount to the cost of care in pregnancy and in the first and second years after birth. Public hospitals funders were 
Table 4. Mean Costs to Different Funders of Maternity Care by Type of Birth Over the First 1000 Days, Queensland, Australia 01/07/2012 - 30/06/2014

\begin{tabular}{|c|c|c|c|}
\hline \multirow{2}{*}{ Funding Source } & \multicolumn{3}{|c|}{ Birth Location and Funding Type } \\
\hline & Private Hospital, n = 44254 & Public Hospital, Public Patient, n = 105343 & Public Hospital, Private Patient, $n=6113$ \\
\hline \multicolumn{4}{|c|}{ Vaginal Birth, No Instruments } \\
\hline Total costs & $\$ 20,964$ & $\$ 18,521$ & $\$ 18,741$ \\
\hline Medicare & $\$ 6,210$ & $\$ 3,350$ & $\$ 4,052$ \\
\hline PBS & $\$ 179$ & $\$ 228$ & $\$ 208$ \\
\hline Public hospital funders & $\$ 2,144$ & $\$ 14,291$ & $\$ 12,267$ \\
\hline Private health insurance & $\$ 9,538$ & $\$ 225$ & $\$ 1,299$ \\
\hline Individual out of pocket & $\$ 2,893$ & $\$ 426$ & $\$ 916$ \\
\hline \multicolumn{4}{|c|}{ Vaginal Birth, With Instruments } \\
\hline Total costs & $\$ 22,723$ & $\$ 21,334$ & $\$ 22,110$ \\
\hline Medicare & $\$ 7,309$ & $\$ 3,738$ & $\$ 4,202$ \\
\hline PBS & $\$ 150$ & $\$ 196$ & $\$ 132$ \\
\hline Public hospital funders & $\$ 1,821$ & $\$ 16,483$ & $\$ 15,321$ \\
\hline Private health insurance & $\$ 10,068$ & $\$ 308$ & $\$ 1,454$ \\
\hline Individual out of pocket & $\$ 3,375$ & $\$ 609$ & $\$ 1,001$ \\
\hline \multicolumn{4}{|c|}{ Caesarean Section Birth } \\
\hline Total costs & $\$ 28,244$ & $\$ 31,939$ & $\$ 33,257$ \\
\hline Medicare & $\$ 8,091$ & $\$ 3,907$ & $\$ 5,563$ \\
\hline PBS & $\$ 296$ & $\$ 321$ & $\$ 325$ \\
\hline Public hospital funders & $\$ 3,068$ & $\$ 26,789$ & $\$ 22,744$ \\
\hline Private health insurance & $\$ 13,526$ & $\$ 366$ & $\$ 3,226$ \\
\hline Individual out of pocket & $\$ 3,263$ & $\$ 557$ & $\$ 1,399$ \\
\hline
\end{tabular}

Abbreviation: PBS, Pharmaceutical Benefits Scheme.

Table 5. Estimated Savings to Different Funders if Caesarean Section Rates Between 2012 and 2014 Were at the Optimal Rate Across Australia, as Estimated by the WHO's C-Model

\begin{tabular}{|c|c|c|c|}
\hline Funding Sources & $\begin{array}{l}\text { Private Hospital Births, } \\
\qquad \text { N = } 264987\end{array}$ & $\begin{array}{l}\text { Public Hospital, Public Patient Births, } \\
\qquad \mathrm{N}=601511\end{array}$ & $\begin{array}{l}\text { Public Hospital, Private Patient Births, } \\
\qquad \mathrm{N}=35334\end{array}$ \\
\hline Medicare & $\$ 89199965$ & $\$ 26733638$ & $\$ 14011992$ \\
\hline PBS & $\$ 7733636$ & $\$ 6721850$ & $\$ 717212$ \\
\hline Public hospital funders & $\$ 28129836$ & $\$ 897690963$ & $\$ 48004709$ \\
\hline Private health insurance & $\$ 192169683$ & $\$ 4965237$ & $\$ 19146,185$ \\
\hline Individual out of pocket & $\$ 1822186$ & $\$ 6439079$ & $\$ 5838851$ \\
\hline Total & $\$ 319055306$ & $\$ 942550306$ & $\$ 87718949$ \\
\hline
\end{tabular}

Abbreviations: WHO, World Health Organization; PBS, Pharmaceutical Benefits Scheme.

the main contributors to public hospital births, regardless of whether women were admitted as a private or public patient. Caesarean section birth cost all funders more than vaginal births with or without instruments, but particularly public hospital funders, private health insurers and Medicare. However, all funders could stand to make considerable savings - \$974 million for public hospital funders, and \$216 million for private health insurers - if caesarean section rates across Australia were reduced to more optimal levels.

The results of this study must be considered alongside the limitations of the analyses, the key limitation being the use of the C-Model methodology to quantify the optimal rate of caesarean section use based upon population-level characteristics. It is impossible to accurately identify which caesarean sections were based on medical indications and which were not, without an individual assessment of clinical notes. As such, this paper has relied upon the best available evidence to quantify expected population-level rates. However, it is known that the caesarean section rates in Australia are higher than the average reported for the Organisation for Economic Co-operation and Development, ${ }^{37}$ and that the rates of caesarean section in low risk (selected) age-standardised women in private care in Queensland is almost 1.6 times that of publicly funded women, which is the greatest variation in Australia. ${ }^{38}$ Other studies have also estimated the reduction in public hospital caesarean rates that 
would be possible if 'best practice' was implemented across all hospitals. ${ }^{39}$ An additional weakness of this paper is the use of mean costs to private health insurers per inpatient episode associated with private hospital use, as opposed to identifying the exact amount paid per service. Currently, these data are not available for linkage at the population level. Finally, it should be emphasised that this study sought to describe the costs of current care to different funders identifying how much each funder currently pays, and so unadjusted means are presented. The characteristics of women seeking care under different funding models may explain some of the variation.

This study has demonstrated that caesarean section is the mode of birth that is most costly to all funders. The rates of caesarean section in private and public hospitals are higher than that estimated based upon population-level risk factors, with almost half of women in private care having a caesarean section (47\%), despite women with more pregnancy and medical complications giving birth in public hospitals. The higher rate of caesarean section birth in private hospitals has resulted in births, on average costing more in private hospitals than public hospital public patient births. This was similar for the difference in costs between public hospital public patient births and public hospital private patients births, with rates of caesarean section being higher in the later. However, costs would also have been higher for this group due to the multiple sources of funding public hospitals can claim for private patients. In addition to receiving payment for the activity through public hospital funding agreements, public hospitals and the treating clinicians will also receive funding from private health insurers, Medicare and potentially individuals through out of pocket fees.

The distributional issues associated with public subsidisation of caesarean section in the private sector, with its demonstrated long-term morbidity impacts, ${ }^{16}$ also warrants consideration. While private hospital care may reduce the burden on public hospitals, and thus reduce the cost to public hospitals associated with maternity care, the public still funds a significant portion of private hospital births as this study has demonstrated. Births in private hospitals cost Medicare about twice the amount as public births in public hospitals over the first 1000 days. Furthermore, the overall costs to governments associated with private care are significantly higher than what they would have been had there been lower rates of caesarean section. Recent reforms to Medicare have directly sought to address the overuse of caesarean section in the private sector. ${ }^{40}$ The government rebate to private obstetricians for caesarean section and vaginal birth was equalised in 2017 to remove the previous financial incentive for caesarean sections, and thus reduce costs to Medicare. However, this only covers one occasion of service, and in total the cost to Medicare for caesarean section is considerably higher than other modes of birth.

Recent attention has been given to the overuse of caesarean section worldwide. ${ }^{41}$ Whilst some parts of the world have considerable mortality and morbidity associated with caesarean section not being available when needed, in highincome countries there is the converse: with considerable morbidity experienced by the overuse of the procedure. ${ }^{16}$ It is already known that caesarean section in Australia is associated with additional operating theatre time, specialist obstetrician, anaesthetist, and midwifery care, allied health and pharmacy time and pharmaceutical costs compared to vaginal births. ${ }^{32}$ This paper has highlighted that most of the costs of health service use across the first 1000 days occur at the time of birth, with the cost of caesarean section the largest contributor.

Given that the largest risk factor for having a caesarean section is having had a previous caesarean section, ${ }^{42}$ attention should be given to reducing caesarean section rates in nulliparous women and those with previous caesarean section births. A number of interventions - caseload midwifery, ${ }^{43}$ chart audit ${ }^{44}$ and induction of labour ${ }^{45}$ - have been shown to reduce the risk of caesarean section amongst low-risk nulliparous women. However, caseload midwifery has been shown to be the most cost-effective option. ${ }^{46}$ Caseload midwifery could yield significant cost-savings to all funders. Alternate strategies to reduce the cost of caesarean section, such as reducing the length of stay of patients who have a caesarean section could also be considered. ${ }^{47}$ In addition, the WHO has made a number of recommendations about non-clinical interventions to reduce unnecessary caesarean section, such as antenatal education for women, evidencebased clinical practice guidelines and mandatory second opinion for caesarean section, a collaborative midwifery obstetrician model of care in which the obstetrician provides in-house labour and delivery coverage 24 hours a day, and financial strategies for healthcare professionals or healthcare organisations. ${ }^{48}$

This study highlights that there is a complex interplay between the costs of maternity care and the outcomes that are produced. Total costs to all funders are lowest on average in public hospital, public patients. The rate of caesarean section deliveries, which are more expensive than other birth types, are higher in private hospitals. All funders, but particularly public hospital, private health insurers and Medicare would see cost savings if caesarean section rates were lower in Australia and in line with optimal rates.

Ethical issues

Ethics approval has been obtained from the Townsville Hospital and Health Service Human Research Ethics Committee (HREC) (HREC/16/QTHS/223), and the Australian Institute of Health and Welfare HREC (EO2017-1-338). We have also obtained Public Health Act Approval (RD007377).

Competing interests

Authors declare that they have no competing interests.

Authors' contributions

EC conceived and designed the study. EC and HF acquitted the data. EC drafted the manuscript, and undertook the statistical analysis. All authors contributed to the analysis and interpretation of the data and critical revision of the manuscript for important intellectual content.

Funding

EC received funding from the National Health and Medical Research Council, NN received funding from the Financial Markets Foundation for Children.

Authors' affiliations

${ }^{1}$ Menzies Health Institute Queensland, Griffith University, Southport, QLD, 
Australia. ${ }^{2}$ Children's Hospital at Westmead Clinical School, Faculty of Medicine and Health, University of Sydney, Sydney, NSW, Australia. ${ }^{3}$ Department of Maternal Fetal Medicine, Royal Hospital for Women, Randwick, NSW, Australia. ${ }^{4}$ School of Medicine, Griffith University, Southport, QLD, Australia. ${ }^{5}$ School of Nursing and Midwifery, Griffith University, Meadowbrook, QLD, Australia.

\section{References}

1. Woo VG, Lundeen T, Matula S, Milstein A. Achieving higher-value obstetrical care. Am J Obstet Gynecol. 2017;216(3):250.e251-250. e214. doi:10.1016/j.ajog.2016.12.033

2. Levy BS, Mukherjee D. Changes in obstetrics and gynecologic care healthcare triple aims: moving women's healthcare from volume to value. Clin Obstet Gynecol. 2015;58(2):355-361. doi:10.1097/ grf.0000000000000099

3. van den Berg N, Radicke F, Stentzel U, Hoffmann W, Flessa S. Economic efficiency versus accessibility: planning of the hospital landscape in rural regions using a linear model on the example of paediatric and obstetric wards in the northeast of Germany. BMC Health Serv Res. 2019;19(1):245. doi:10.1186/s12913-019-4016-2

4. Australian Institute of Health and Welfare (AIHW). Health Expenditure Australia 2016-2017. Canberra: AlHW; 2018.

5. Whitman E. Delivering new bundles to control cost of maternal care. Mod Healthc. 2016;46(33):8-10.

6. Independent Hospital Pricing Authority (IHPA). Bundled Pricing for Maternity Care. Sydney: IHPA; 2017

7. Pomeroy AM, Koblinsky M, Alva S. Who gives birth in private facilities in Asia? a look at six countries. Health Policy Plan. 2014;29 Suppl 1:i38-47. doi:10.1093/heapol/czt103

8. Tapay N, Colombo F. Private Health Insurance in OECD Countries: The Benefits and Costs for Individuals and Health Systems. Paris: OECD; 2004.

9. Paris V, Devaux M, Wei L. Health Systems Institutional Characteristics. Paris: OECD; 2010.

10. Morgan R, Ensor T, Waters H. Performance of private sector health care: implications for universal health coverage. Lancet. 2016;388(10044):606-612. doi:10.1016/s0140-6736(16)00343-3

11. Lutomski JE, Murphy M, Devane D, Meaney S, Greene RA. Private health care coverage and increased risk of obstetric intervention. BMC Pregnancy Childbirth. 2014;14:13. doi:10.1186/1471-2393-1413

12. Dahlen HG, Tracy S, Tracy M, Bisits A, Brown C, Thornton C. Rates of obstetric intervention and associated perinatal mortality and morbidity among low-risk women giving birth in private and public hospitals in NSW (2000-2008): a linked data populationbased cohort study. BMJ Open. 2014;4(5):e004551. doi:10.1136/ bmjopen-2013-004551

13. Coulm B, Le Ray C, Lelong N, Drewniak N, Zeitlin J, Blondel B. Obstetric interventions for low-risk pregnant women in France: do maternity unit characteristics make a difference? Birth. 2012;39(3):183-191. doi:10.1111/j.1523-536X.2012.00547.x

14. Mossialos E, Allin S, Karras K, Davaki K. An investigation of caesarean sections in three Greek hospitals: the impact of financial incentives and convenience. Eur J Public Health. 2005;15(3):288295. doi:10.1093/eurpub/cki002

15. Di Lallo D, Perucci CA, Bertollini R, Mallone S. Cesarean section rates by type of maternity unit and level of obstetric care: an area-based study in central Italy. Prev Med. 1996;25(2):178-185. doi:10.1006/pmed.1996.0044

16. Sandall J, Tribe RM, Avery L, et al. Short-term and long-term effects of caesarean section on the health of women and children. Lancet. 2018;392(10155):1349-1357. doi:10.1016/s0140-6736(18)31930-5

17. Petrou S, Henderson J, Glazener C. Economic aspects of caesarean section and alternative modes of delivery. Best Pract Res Clin Obstet Gynaecol.2001;15(1):145-163. doi:10.1053/beog.2000.0154

18. Henderson J, McCandlish R, Kumiega L, Petrou S. Systematic review of economic aspects of alternative modes of delivery. BJOG. 2001;108(2):149-157. doi:10.1111/j.1471-0528.2001.00044.x

19. Heer IM, Kahlert S, Rummel S, Kümper C, Jonat W, Strauss A. Hospital treatment - Is it affordable? a structured cost analysis of vaginal deliveries and planned caesarean sections. Eur J Med Res. 2009;14(11):502-506. doi:10.1186/2047-783x-14-11-502
20. Clark L, Mugford M, Paterson C. How does the mode of delivery affect the cost of maternity care? Br J Obstet Gynaecol. 1991;98(6):519523. doi:10.1111/j.1471-0528.1991.tb10362.x

21. $\mathrm{Xu} X$, Gariepy A, Lundsberg LS, et al. Wide variation found in hospital facility costs for maternity stays involving low-risk childbirth. Health Aff (Millwood). 2015;34(7):1212-1219. doi:10.1377/ hlthaff.2014.1088

22. Young D, Twaddle S, Lees $A$. The costs to the NHS of maternity care: midwife-managed vs shared. Br J Midwifery. 1997;5(8):465472. doi:10.12968/bjom.1997.5.8.465

23. Howell E, Palmer A, Benatar S, Garrett B. Potential Medicaid cost savings from maternity care based at a freestanding birth center. Medicare Medicaid Res Rev. 2014;4(3). doi:10.5600/mmrr.004.03. a06

24. Australian Government. Medicare Levy Reduction for Low-Income Earners. Australian Taxation Office. Medicare Levy Web site. https://www.ato.gov.au/individuals/medicare-levy/medicare-levyreduction-for-low-income-earners/. Published 2017. Accessed October 16, 2017.

25. Department of Human Services. Australian Government rebate on Private Health Insurance. Australian Government. https://www. humanservices.gov.au/individuals/services/medicare/australiangovernment-rebate-private-health-insurance\#a2. Published 2019. Accessed May 1, 2019.

26. Australian Government. Medicare Levy Surcharge. Australian Taxation Office. Medicare Levy Web site. https://www.ato.gov.au/ individuals/medicare-levy/medicare-levy-surcharge/. Published 2017. Accessed October 16, 2017.

27. Australian Bureau of Statistics (ABS). 4364.0.55.002 - Health Service Usage and Health Related Actions, Australia, 2014-2015. Canberra: ABS; 2017.

28. Australian Institute of Health and Welfare (AlHW). Australia's Mothers and Babies 2015-In Brief. Canberra: AlHW; 2017.

29. Moore TG, Arefadib N, Deery A, Keyes M, West S. The First Thousand Days: An Evidence Paper. Melbourne, Australia: Murdoch Children's Research Institute; 2017.

30. Callander EJ, Fox H. What are the costs associated with child and maternal healthcare within Australia? a study protocol for the use of data linkage to identify health service use, and health system and patient costs. BMJ Open. 2018;8(2):e017816. doi:10.1136/ bmjopen-2017-017816

31. Reserve Bank of Australia (RBA). Measures of Consumer Price Inflation. RBA; 2017.

32. Independent Hospital Pricing Authority (IHPA). National Hospital Cost Data Collection, Public Hospitals Cost Report, Round 22. Sydney: IHPA; 2020.

33. Australian Government Department of Health. Archived Private Hospital Data Bureau (PHDB) Annual Reports. http://health.gov. au/internet/main/publishing.nsf/Content/health-casemix-datacollections-publications-PHDBAnnualReports.

34. Souza JP, Betran AP, Dumont A, et al. A global reference for caesarean section rates (C-Model): a multicountry cross-sectional study. BJOG. 2016;123(3):427-436. doi:10.1111/1471-0528.13509

35. Zucchelli E, Jones AM, Rice N. The evaluation of health policies through microsimulation methods. In: Health, Econometrics and Data Group (HEDG) Working Papers. York: University of York; 2010. Vol 10.

36. Bell P. GREGWT and TABLE Macros-Users Guide. Canberra: Australian Bureau of Statistics (ABS); 2000.

37. Organisation for Economic Co-operation and Development (OECD). Caesarean Section Rates, 2013. Paris: OECD; 2015.

38. Australian Commission on Safety and Quality in Health Care. Australian Atlas of Healthcare Variation. Canberra: Australian Government; 2017.

39. Lee YY, Roberts CL, Patterson JA, et al. Unexplained variation in hospital caesarean section rates. Med J Aust. 2013;199(5):348-353. doi:10.5694/mja13.10279

40. Department of Health. Changes to MBS Items for Obstetrics Services. Canberra: Australian Government; 2017.

41. Boerma T, Ronsmans C, Melesse DY, et al. Global epidemiology of use of and disparities in caesarean sections. Lancet. 
2018;392(10155):1341-1348. doi:10.1016/s0140-6736(18)31928-7

42. Slavin V, Fenwick J. Use of a classification tool to determine groups of women that contribute to the cesarean section rate: establishing a baseline for clinical decision making and quality improvement. Int J Childbirth. 2012;2(2):85-95. doi:10.1891/2156-5287.2.2.85

43. McLachlan HL, Forster DA, Davey MA, et al. Effects of continuity of care by a primary midwife (caseload midwifery) on caesarean section rates in women of low obstetric risk: the COSMOS randomised controlled trial. BJOG. 2012;119(12):1483-1492. doi:10.1111/j.1471-0528.2012.03446.x

44. Johri M, Ng ESW, Bermudez-Tamayo C, Hoch JS, Ducruet T, Chaillet N. A cluster-randomized trial to reduce caesarean delivery rates in Quebec: cost-effectiveness analysis. BMC Med. 2017;15(1):96. doi:10.1186/s12916-017-0859-8
45. Grobman WA, Rice MM, Reddy UM, et al. Labor induction versus expectant management in low-risk nulliparous women. $N$ Engl $J$ Med. 2018;379(6):513-523. doi:10.1056/NEJMoa1800566

46. Callander EJ, Creedy DK, Gamble J, et al. Reducing caesarean delivery: an economic evaluation of routine induction of labour at 39 weeks in low-risk nulliparous women. Paediatr Perinat Epidemiol. 2020;34(1):3-11. doi:10.1111/ppe.12621

47. Bowden SJ, Dooley W, Hanrahan J, et al. Fast-track pathway for elective caesarean section: a quality improvement initiative to promote day 1 discharge. BMJ Open Qual. 2019;8(2):e000465. doi:10.1136/bmjoq-2018-000465

48. Murphy J, Murray S, Chalmers J, Martin S, Marston G. Half a citizen: life on welfare in Australia. Melbourne: Allen \& Unwin; 2011. 